\title{
Ciliary Neurotrophic Factor Receptor $\alpha$ in Spinal Motoneurons is Regulated by Gonadal Hormones
}

\author{
Nancy G. Forger, ${ }^{1}$ Christine K. Wagner, ${ }^{1}$ Michael Contois, ${ }^{1}$ Lynn Bengston, ${ }^{1}$ and A. John MacLennan ${ }^{2}$ \\ ${ }^{1}$ Center for Neuroendocrine Studies and Department of Psychology, University of Massachusetts, Amherst, \\ Massachusetts 01003, and '2Department of Neuroscience, University of Florida Brain Institute, University of Florida \\ College of Medicine, Gainesville, Florida 32610
}

Ciliary neurotrophic factor receptor $\alpha(\mathrm{CNTFR} \alpha)$ is the ligandbinding component of the CNTF receptor. CNTFR $\alpha$ expression is essential for the normal development of spinal motoneurons and is required for the development of a sex difference in motoneuron number in androgen-sensitive perineal motoneurons. We used immunocytochemistry to examine the expression and hormone regulation of CNTFR $\alpha$ protein in the spinal nucleus of the bulbocavernosus (SNB), dorsolateral nucleus and retrodorsolateral nucleus of the lower lumbar spinal cord of adult rats. CNTFR $\alpha$ immunoreactivity (CNTFR $\alpha-\mathrm{IR})$ was observed in the somata and dendrites of virtually all motoneurons. In all three motor pools, the intensity of motoneuron soma labeling was greatest among gonadally intact males and was reduced in females and gonadectomized males. The density of CNTFR $\alpha$-IR in neuropil also tended to be highest in intact males. Short-term (2 d) testosterone propionate treatment reversed the decline in the density of soma labeling in the SNB of castrated males but did not reverse any other effects of castration. Long-term hormone treatment, achieved by implanting males with testosterone capsules at the time of gonadectomy, prevented the decline in soma labeling in all motor pools and partially prevented the decline in neuropil label caused by castration. We conclude that expression of CNTFR $\alpha$ protein is androgen-regulated in spinal motoneurons.

Key words: motoneuron; androgen; ciliary neurotrophic factor receptor; spinal cord; immunocytochemistry; hormone
Ciliary neurotrophic factor (CNTF) was first identified based on its ability to prevent the death of parasympathetic neurons of the ciliary ganglion (Barbin et al., 1984) but, subsequently, has gained substantial attention as a potent motoneuron trophic factor. CNTF can prevent the death of developing motoneurons (Arakawa et al., 1990; Sendtner et al., 1990; Oppenheim et al., 1991) and supports multiple innervation of striated muscles during the period of synapse elimination (Jordan, 1996). In postweaning and adult animals, administration of CNTF promotes motor nerve sprouting at the neuromuscular junction (Gurney et al., 1992), enhances muscle fiber reinnervation after nerve injury (Sahenk et al., 1994; Ulenkate et al., 1994), and reduces motoneuron death in animal models of neuromuscular disease (Sendtner et al., 1992; Mitsumoto et al., 1994; Ikeda et al., 1995; Sagot et al., 1995). Deletion of the CNTF gene results in subtle motor impairments in adult mice (Masu et al., 1993).

The actions of CNTF are mediated via a three-part receptor complex consisting of a CNTF-binding component, CNTFR $\alpha$, and two signal transducing components, gp130 and LIFR $\beta$ (Davis et al., 1993). Expression of CNTFR $\alpha$ is restricted primarily to cells of the nervous system (Davis et al., 1991; Ip et al., 1993; MacLennan et al., 1994), with motoneurons of adult rats expressing high levels of CNTFR $\alpha$ protein and mRNA (MacLennan et al., 1996; Lee et al., 1997b). Mice with a targeted deletion of the CNTFR $\alpha$ gene exhibit reduced motoneuron number at birth and early postnatal mortality (DeChiara et al., 1995).

\footnotetext{
Received May 27, 1998; revised Aug. 20, 1998; accepted Aug. 20, 1998.

Supported by National Institutes of Health Grants NS35224, HD33044, HD01188 and the Whitehall Foundation. We thank Karen Neitzel and Brenda Devlin for technical assistance.

Correspondence should be addressed to Nancy G. Forger, Department of Psychology, University of Massachusetts, Amherst, MA 01003-7710.

Copyright (C) 1998 Society for Neuroscience $\quad 0270-6474 / 98 / 188720-10 \$ 05.00 / 0$
}

In addition to expression of $\operatorname{CNTFR} \alpha$, many brainstem and spinal motoneurons express androgen receptors and are sensitive to androgens in adulthood (Sar and Stumpf, 1977; Yu and McGinnis, 1986). For example, androgens accelerate the rate of motor axon regeneration after injury to the sciatic, facial, and hypoglossal nerves (Yu, 1982; Kujawa and Jones, 1990; Kujawa et al., 1993, 1995). The sexually dimorphic perineal motoneurons of the lower lumbar spinal cord exhibit exceptional androgen sensitivity. The spinal nucleus of the bulbocavernosus (SNB) and dorsolateral nucleus (DLN) of rodents innervate striated muscles that attach to the base of the penis (Schroder, 1980). SNB and DLN cell survival is dependent on androgens during perinatal life and, as a result, males retain many more of these motoneurons than do females (Breedlove and Arnold, 1980; Nordeen et al., 1985; Sengelaub and Arnold, 1989). In adulthood the soma size and dendritic extent of SNB and DLN motoneurons are increased by androgens (Breedlove and Arnold, 1981; Kurz et al., 1986, 1991).

We have recently shown that CNTF mimics some effects of testosterone on perineal motoneurons. For example, CNTF prevents the death of SNB motoneurons in perinatal female rats (Forger et al., 1993). Moreover, the normal sex difference in SNB cell number is absent in CNTFR $\alpha$ knock-out mice (Forger et al., 1997), suggesting that androgen cannot rescue these motoneurons in animals lacking functional CNTF receptors. The molecular mechanisms whereby androgens influence motoneuron survival, soma size, dendritic extent, or speed of regeneration after injury are not known but may involve hormonal modulation of the expression of trophic factors and/or their receptors. We, therefore, asked whether CNTFR $\alpha$ expression is androgen-regulated in lumbar motoneurons of adult rats. 


\section{MATERIALS AND METHODS}

\section{Animals}

Sprague Dawley rats were purchased from Taconic (Germantown, NY) and housed two per cage in a 14/10 light/dark cycle with food and water available ad libitum. Gonadectomies and sham gonadectomies were performed via a single midline incision under Metofane anesthesia.

\section{Experiment 1}

This experiment was designed to compare CNTFR $\alpha$ immunoreactivity (CNTFR $\alpha$-IR) in adult males and females and to examine effects of gonadectomy and short-term testosterone replacement on CNTFR $\alpha$-IR of males. Young adult male rats, 57-67 d of age, were gonadectomized $(\mathrm{Gdx})$ or sham-gonadectomized. Adult females of the same age were unoperated. Twenty-six days after surgery half of the $\mathrm{Gdx}$ males received two daily injections of testosterone propionate (TP; $500 \mu \mathrm{g} / \mathrm{d}$ ) dissolved in $250 \mu \mathrm{l}$ sesame oil. All other animals received two daily injections of the oil vehicle. Four treatment groups resulted: Sham males, Gdx + oil males, Gdx $+2 \mathrm{~d}$ TP males, and Females ( $n=4$ animals per group). Animals were killed $24 \mathrm{hr}$ after the last injection (4 weeks after surgery), and immunocytochemistry for CNTFR $\alpha$ was performed in four yoked runs, each run examining tissue from one animal of each of the four groups.

\section{Experiment 2}

Short-term (48 hr) testosterone replacement was ineffective in reversing most effects of castration in experiment 1 (see below). Therefore, we next examined the effects of gonadectomy and long-term testosterone treatment on CNTFR $\alpha$-IR in motoneurons of adult males. Male Sprague Dawley rats, $72 \mathrm{~d}$ of age, were gonadectomized $(n=12)$ or sham gonadectomized $(n=6)$. At the time of surgery each animal received a SILASTIC capsule implanted subcutaneously at the nape of the neck. Half of the Gdx males $(\mathrm{Gdx}+\mathrm{T})$ received capsules filled with crystalline testosterone (Sigma, St. Louis, MO). The size of the tubing $(45 \mathrm{~mm}$ length; $1.67 \mathrm{~mm}$ inner diameter, $3.18 \mathrm{~mm}$ outer diameter) was chosen to provide plasma testosterone levels in the high physiological range (Smith et al., 1977). The remaining males received empty capsules of the same size ( $\mathrm{Gdx}+$ Blank and Sham groups). Capsules remained in place until animals were killed at 7 weeks after surgery. Seminal vesicle weights were recorded at the time of killing as an indirect measure of recent circulating androgen levels, and immunocytochemistry for CNTFR $\alpha$ was performed in two runs, with spinal cords of two animals from each group in each run.

\section{Immunocytochemistry}

Animals were perfused with cold saline followed by $4 \%$ paraformaldehyde. Spinal cords were removed and post-fixed in $4 \%$ paraformaldehyde for $2 \mathrm{hr}$, then transferred to $15 \%$ sucrose $/ 0.1 \mathrm{~m}$ phosphate buffer, $\mathrm{pH} 7.2$, containing $2.5 \mathrm{~mm}$ sodium azide overnight. Thirty micrometer coronal sections were cut on a cryostat through the lumbosacral spinal cord, and every fifth section (experiment 1) or every fourth section (experiment 2) was retained for processing. To compare the expression of CNTFR $\alpha$ in the lower lumbar spinal cord with expression in other spinal regions the entire spinal cords of several additional adult males were removed, and segments (5-10 mm long) of the cervical, thoracic, and lumbar cord were cryostat-sectioned in the horizontal plane.

Detection of CNTFR $\alpha$ protein was performed by a modification of the procedure described in MacLennan et al. (1996). Free-floating sections were rinsed in PBS, and endogenous peroxidase activity was quenched by an incubation in $0.3 \% \mathrm{H}_{2} \mathrm{O}_{2}$ in methanol for $30 \mathrm{~min}$. Tissues were then rinsed in PBS and exposed to a blocking solution [0.3\% Triton X-100, $0.03 \%$ bovine serum albumin (BSA), and $10 \%$ normal goat serum in PBS] for $1 \mathrm{hr}$, then incubated for $3 \mathrm{~d}$ at $4^{\circ} \mathrm{C}$ in a $1: 200$ dilution of affinity-purified polyclonal antiserum " $3 X$ " (MacLennan et al., 1996). Sections were sequentially washed, incubated for $1 \mathrm{hr}$ with goat antirabbit biotinylated secondary antibody, washed again, and incubated for $1 \mathrm{hr}$ in an avidin-biotin-peroxidase conjugate (Vectastain Elite ABC kit, Vector Laboratories, Burlingame, CA) and stained using 3,3'diaminobenzidine as a substrate and nickel ammonium sulfate as an enhancer.

All label was abolished when the primary antiserum was omitted (data not shown). Previously, MacLennan et al. (1996) used Western blotting to demonstrate that the $3 \mathrm{X}$ antiserum selectively recognizes a protein species in adult rat brain that migrates with an apparent molecular weight of $78 \mathrm{kDa}$, consistent with the interpretation that this antiserum is selective for the $\sim 80 \mathrm{kDa}$ CNTFR $\alpha$ protein. In addition, all $3 \mathrm{X}$ label in rat spinal cord and brain was eliminated when the antiserum was preadsorbed with the immunizing peptide (MacLennan et al., 1996).

\section{Computer-aided image analysis}

CNTFR $\alpha$-IR was quantified in the SNB, DLN, and retrodorsolateral nucleus (RDLN) of lumbar spinal segments 5 and 6. SNB and DLN motoneurons innervate the sexually dimorphic penile muscles (Schroder, 1980), whereas RDLN motoneurons primarily innervate intrinsic muscles of the foot that are present in both sexes (Nicolopoulos-Stournaras and Iles, 1983).

All measurements were made by an investigator blind to the sex and endocrine status of the animals. Images were captured with an Olympus BH-2 microscope fitted with a CCD72 (Dage MTI, Michigan City, MI) camera that was connected to a QuickCapture frame grabber board (Data Translation Inc., Marlboro, MA) in a Macintosh IIfx computer. NIH Image 1.57 software (W. Rasbaud, National Institutes of Health, Bethesda, MD) was used to analyze captured images. The "sharpen" function was applied once to all captured images before quantification.

\section{Selection of sections for analysis}

To eliminate from analysis sections in which label was poor, or in which one of the three cell groups (RDLN, DLN, or SNB) was absent, we first identified those sections that had the greatest number of pixels above threshold in the ventral horn. To perform this selection, images were captured using a low-power objective $(4 \times)$. Mean background labeling and SD of background label were measured bilaterally in each section in large oval areas $\left(\sim 1.24 \times 10^{5} \mu \mathrm{m}^{2} ; 7500\right.$ pixels $)$ in the gray matter medial to the RDLN. The "density slice" function was then used to count all pixels above threshold in the ventral horn, with threshold defined as the mean background plus 2.5 times the SD of background density. Six sections through the SNB region of each animal in experiment 1 and 10 sections through the SNB in animals from experiment 2 were initially chosen. This represented 70 and $69 \%$ of all available sections through the SNB regions of the animals in experiments 1 and 2, respectively. All six sections of animals from experiment 1 were subjected to detailed quantitative analysis; 5 of the 10 identified sections of animals in experiment 2 were randomly selected for further quantitative analysis.

Three measures were made of each of the three motoneuron pools in the selected sections. Images were captured using a $20 \times$ objective, and sections from all animals within a given experiment were analyzed in a single session, during which the microscope light intensity and camera settings were kept constant.

Intensity of motoneuron soma labeling. From each section three randomly chosen motoneuron somata in each cell group were traced, and the density of label within the tracings (minus mean background density in that section) was recorded. Optical density measures were then used to classify labeled motoneurons on a four-point scale (light to very dark). Cell density scores from all motoneurons of all animals in a given run were pooled, rank ordered, and separated by quartile. Motoneurons with density scores among the lowest $25 \%$ of all scores were arbitrarily classified as "light", whereas cells in the second, third, and fourth quartiles were classified as "medium", "dark", and "very dark", respectively. The conversion of density readings to a nominal scale, and the subsequent analysis of the resulting relative frequency distributions with nonparametric statistics avoided the necessity of making any assumptions about the linearity of pixel density measures in our system.

Intensity of label in neuropil. Three randomly selected areas of neuropil within each of the three motor nuclei were sampled from each section, and the density (minus background) was recorded. Neuropil scores were then pooled and classified as light, medium, dark, or very dark, as above.

Total area covered by label. The outlines of the RDLN, DLN, and SNB were traced, and the density slice function was used to count all pixels above threshold in each nucleus. The DLN and RDLN were analyzed unilaterally, whereas the SNB, which is located near the midline, was measured bilaterally. Threshold was defined as above, with background label determined in an oval area $\left(\sim 25,000 \mu \mathrm{m}^{2} ; 38,150\right.$ pixels $)$ in the gray matter between the RDLN and DLN. The number of pixels above threshold in each motor pool was summed across sections to obtain the total area covered by label for each animal.

\section{Cell counts}

After the measures described above had been recorded, the coverslips on tissues from animals in experiment 1 were soaked off, and sections were counterstained with neutral red. The number of neutral red-stained 

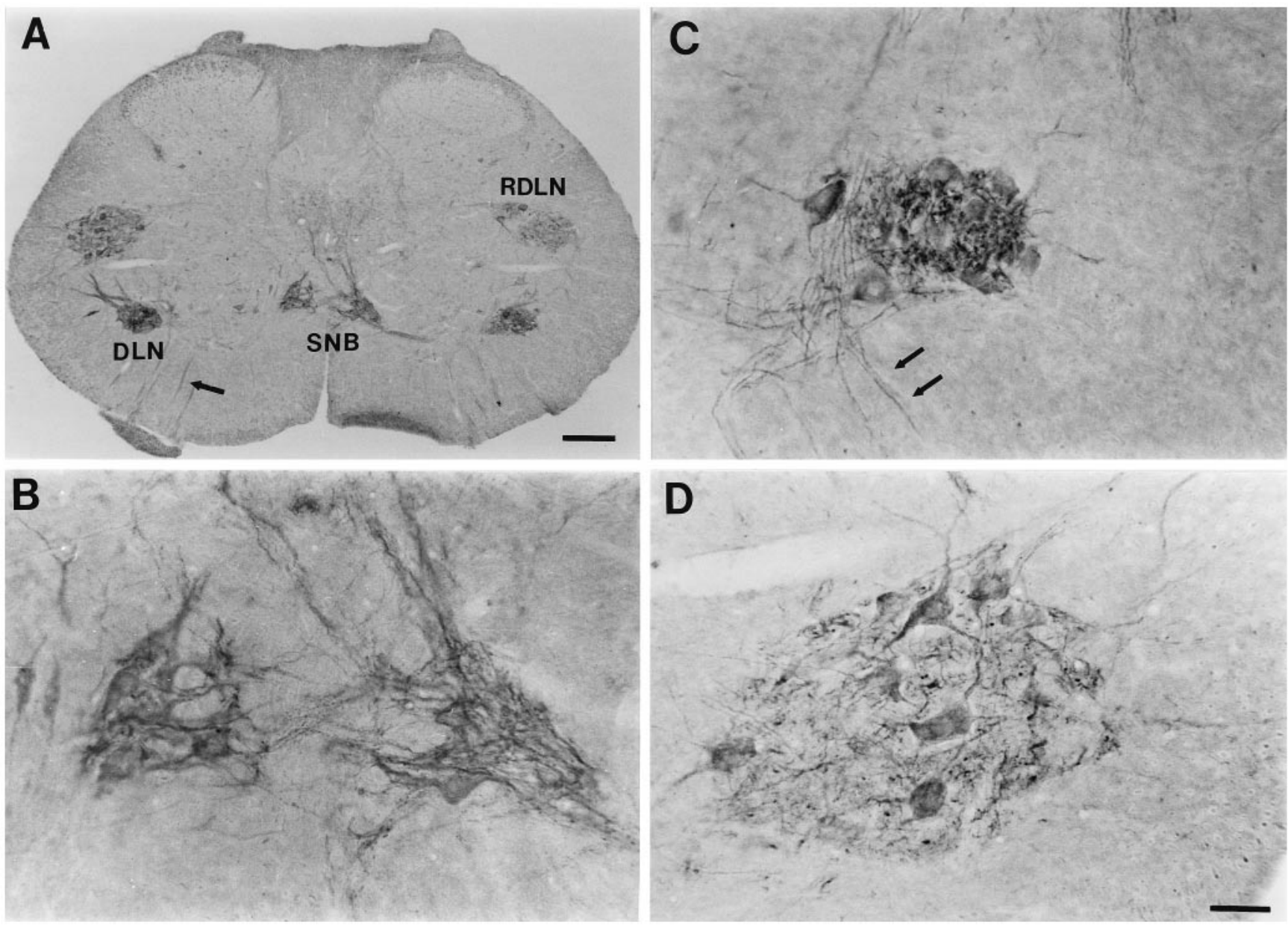

Figure 1. CNTFR $\alpha$ immunoreactivity in the lower lumbar spinal cord of adult male rats. $A$, Low magnification view of a cross section through the spinal cord demonstrating CNTFR $\alpha$-IR in the SNB, DLN, and RDLN motor pools. Scale bar, $200 \mu \mathrm{m}$. $B, D$, Higher magnification of the SNB and left RDLN of the section in $A$. $C$, High magnification view of the DLN (not the same section or animal as in $A$ ) showing the heavily labeled, punctate appearance of the neuropil and the lighter label in motoneuron somata characteristic of this nucleus. Scale bar in $D, 50 \mu \mathrm{m}$ (applies to $B-D)$. Arrows in $A$ and $C$ indicate labeled axons exiting the cord.

motoneuron profiles with a visible nucleolus was then recorded for each motor pool. Mean nucleolus size was determined from camera lucida tracings of $\sim 20$ motoneurons per pool per animal, and was used to correct for split nucleoli by the method of Konigsmark (1970). Because motoneuronal nucleoli are nearly spherical and are small relative to the section thickness used, any bias introduced by this count-correction procedure should be negligible (Clarke and Oppenheim, 1995).

\section{Statistics}

The relative frequency distributions of intensity of motoneuron soma labeling and intensity of label in neuropil were analyzed by $\chi^{2}$ tests for independence. A significant difference in the overall $\chi^{2}$ was followed by $\chi^{2}$ tests comparing each treatment group with the intact male group and contrasting Gdx + oil (or Blank) males with Gdx $+\mathrm{TP}$ (or T) males. Measures of the mean total area covered by label were analyzed by separate one-way ANOVAs for each motor pool, and significant main effects were followed by planned comparisons. Means are reported \pm SEM.

\section{RESULTS}

\section{Distribution of CNTFR $\alpha$ immunoreactivity}

Most CNTFR $\alpha$-IR in the spinal cord was localized to motor pools (Fig. 1). CNTFR $\alpha$-IR was found in the somata and dendrites of motoneurons throughout the spinal cord, and in several cases labeled motoneuronal axons could be seen exiting the ventral horn (Figs. 1, 2). A Nissl counter stain revealed that virtually all motoneurons $(>95 \%)$ were at least lightly labeled, although the intensity of CNTFR $\alpha$-IR differed between motor pools. The DLN of the lower lumbar spinal cord consistently stood out as the most densely labeled cell group. In many instances the DLN presented a striking pattern with intensely labeled, punctate neuropil surrounding lighter motoneuron cell bodies (Fig. 1C). The SNB nucleus also tended to be intensely labeled (Figs. 1B, 2A). Although we did not systematically examine every segment of the spinal cord, we did sample from the cervical, thoracic, and lumbar regions of the cord from several animals. In all regions the motor pools were characterized by CNTFR $\alpha$-IR in somata surrounded by a sparse plexus of labeled neurites (Fig. 2), but in no other region did we observe a pattern comparable to the very intense label characteristic of the DLN and SNB.

\section{Experiment 1: four weeks of castration and short-term testosterone replacement}

Summary of results

CNTFR $\alpha$-IR was darker in the motoneuron somata of shamoperated males than of females or gonadectomized males in all three motor pools. Two days of testosterone treatment eliminated the difference in soma labeling between sham-operated and gonadectomized males in the SNB but not in the DLN or RDLN. 


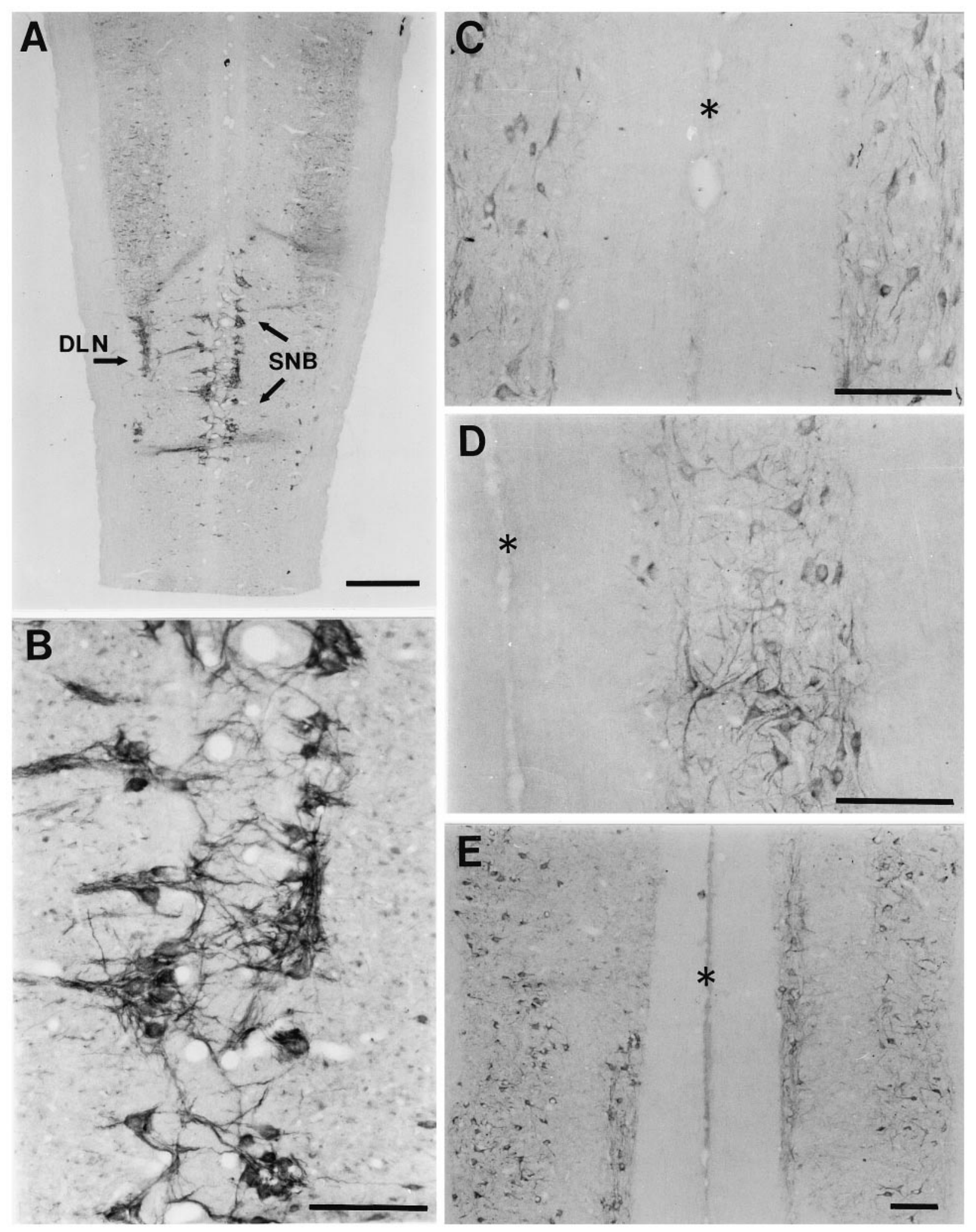

Figure 2. CNTFR $\alpha$ immunoreactivity in horizontal sections of the lumbar and thoracic spinal cord. $A$, Low magnification view through the lower lumbar spinal cord. Immunoreactivity is present in all motor columns but is especially intense in the SNB and DLN. Scale bar, $600 \mu \mathrm{m}$. $B$, Higher magnification view of the SNB region shown in $A$. $C-E$, Upper thoracic, lower thoracic, and upper lumbar spinal cord, respectively. Asterisks indicate the midline in each case. Scale bars in $B-E, 200 \mu \mathrm{m}$. 

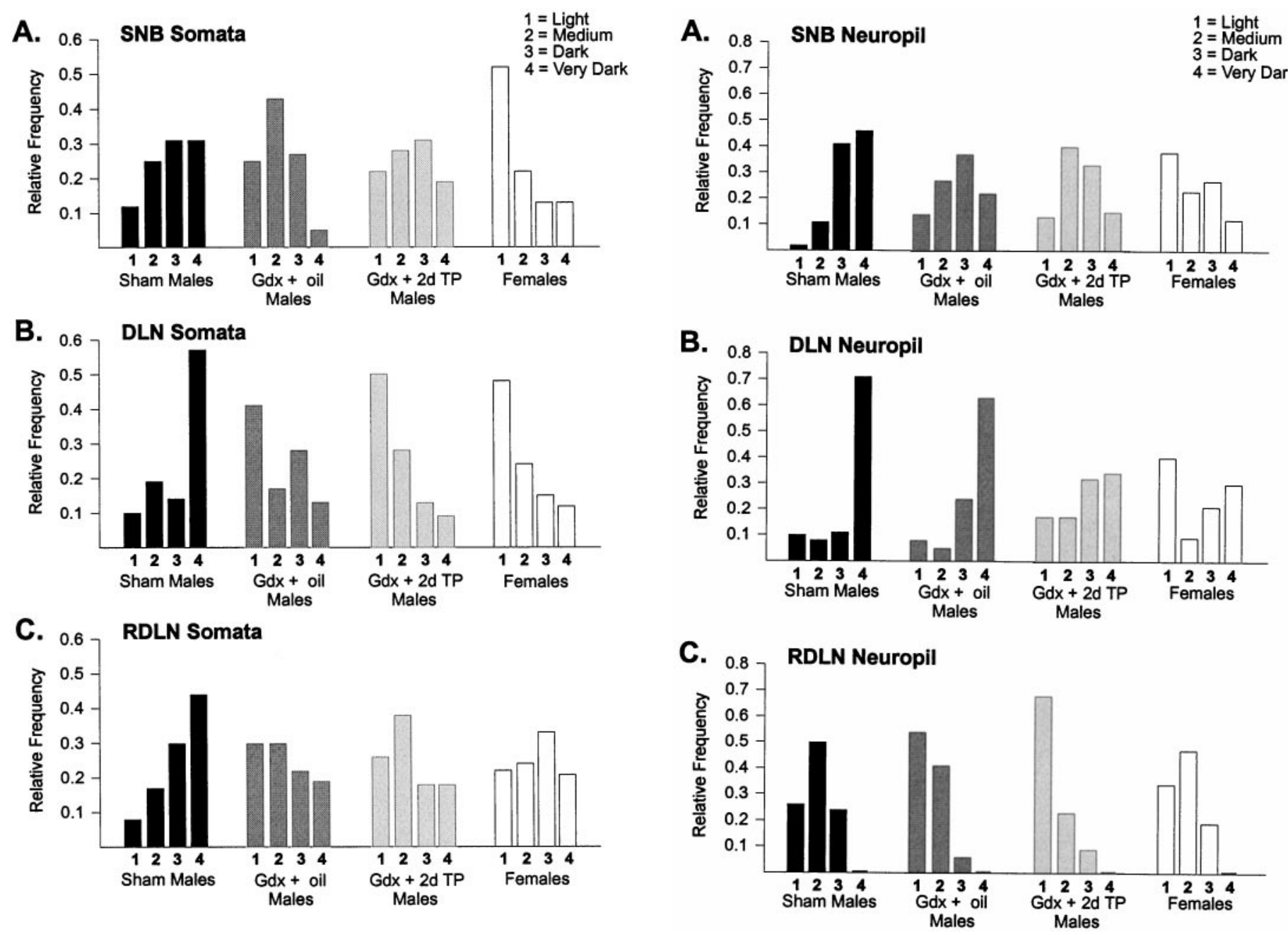

Figure 3. Relative frequency distributions of the percent of motoneuron somata with light, medium, dark, or very dark CNTFR $\alpha$-IR in the animals of experiment 1. $A$, The distribution of label intensities was shifted to higher (darker) values in SNB motoneurons of Sham males than in $G d x+$ oil males or Females. B, $C$, DLN and RDLN soma densities were higher in Sham males than in all other groups.

CNTFR $\alpha$-IR in the neuropil was also more intense in Sham males than in Gdx males in the SNB and RDLN. Two days of TP treatment did not reverse the effects of gonadectomy on neuropil labeling. These results are detailed below.

\section{Intensity of CNTFR $\alpha$-IR in motoneuron somata}

There was a significant difference across treatment groups in the relative frequency distributions of soma labeling in all three motor pools (Fig. 3; SNB: $\chi^{2}=28.4, p<0.005$; DLN: $\chi^{2}=53.4$, $p<0.001$; RDLN: $\left.\chi^{2}=32.3, p<0.001\right)$. SNB motoneuron soma densities were shifted to significantly higher values (darker somas) in Sham males than in Females or Gdx + oil males $(p<0.005$ in both cases, Fig. $3 A$ ). The distribution of soma densities of gonadectomized males receiving $2 \mathrm{~d}$ of testosterone $(\mathrm{Gdx}+2 \mathrm{~d} \mathrm{TP})$ was similar to that of Sham males $(p>0.40)$ but also did not differ significantly from that of $\mathrm{Gdx}+$ oil males $(p>0.10)$.

In the DLN, motoneuron soma density scores of Sham males were shifted to darker values than those of all other groups $(p<$ 0.001 in each case, Fig. $3 B$ ). This is especially clear when comparing the relative frequencies of the most darkly labeled cells; $>50 \%$ of the DLN cells of Sham males were classified as very

Figure 4. Relative frequency distributions of the intensity of CNTFR $\alpha$-IR in the neuropil of animals in experiment 1. A, SNB neuropil densities were higher in Sham males than in any other group. B, DLN neuropil densities were higher in Sham males than in Females or Gdx + $2 d$ TP males. $C$, In the RDLN, Sham males had higher neuropil densities than $G d x+$ oil or $G d x+T P$ males, but neuropil densities did not differ between Sham males and Females.

dark, whereas the relative frequency of very dark cells was $\sim 10 \%$ in all other groups. The $\mathrm{Gdx}+$ oil and $\mathrm{Gdx}+2 \mathrm{~d}$ TP groups did not differ with respect to CNTFR $\alpha$-IR of DLN somata ( $p>$ $0.20)$. RDLN somata of Sham males were shifted to darker values than in any other group ( $p<0.005$ in each case, Fig. $3 C$ ), and the two gonadectomized male groups did not differ on this measure $(p=0.20)$.

\section{Intensity of CNTFR $\alpha$-IR in neuropil}

The relative frequency distributions of neuropil label intensity differed significantly across treatment groups in the $\operatorname{SNB}\left(\chi^{2}=\right.$ 22.9; $p<0.001)$, DLN $\left(\chi^{2}=38.7, p<0.001\right)$, and $\operatorname{RDLN}\left(\chi^{2}=\right.$ $31.3, p<0.001)$. Neuropil densities in the SNB were shifted to higher values in Sham males than in any of the other groups $(p<$ 0.005 in each case; Fig. $4 A$ ), and Gdx $+2 \mathrm{~d}$ TP males did not differ from $\mathrm{Gdx}+$ oil males on this measure $(p>0.50)$. DLN neuropil densities were also higher in Sham males than in Females or Gdx $+2 \mathrm{~d}$ TP males $(p<0.005$; Fig. $4 B)$, but Sham males and Gdx + oil males did not differ significantly $(p>0.05)$. RDLN neuropil density scores in Sham males were shifted to higher values than in 


\begin{tabular}{|c|c|c|c|}
\hline & $\begin{array}{l}\text { RDLN }^{b} \\
\left(\times 10^{3} \text { pixels }\right)\end{array}$ & $\begin{array}{l}\text { DLN } \\
\left(\times 10^{3} \text { pixels }\right)\end{array}$ & $\begin{array}{l}\text { SNB } \\
\left(\times 10^{3} \text { pixels }\right)\end{array}$ \\
\hline Sham males & $123 \pm 12$ & $134 \pm 24$ & $145 \pm 14$ \\
\hline Gdx + oil males & $141 \pm 11$ & $108 \pm 12$ & $144 \pm 25$ \\
\hline $\mathrm{Gdx}+2 \mathrm{~d}$ TP males & $119 \pm 14$ & $101 \pm 19$ & $123 \pm 16$ \\
\hline Females & $167 \pm 14$ & $67 \pm 29$ & $31 \pm 10^{*}$ \\
\hline
\end{tabular}

${ }^{a}$ For each animal the number of pixels covered by label was summed across six sections, $n=4$ animals per group.

${ }^{b}$ The RDLN and DLN were measured unilaterally; the SNB was measured bilaterally.

*Significantly different from each of the male groups, $p<0.015$.

Gdx + oil males or Gdx $+2 \mathrm{~d}$ TP males $(p<0.001$ in both cases; Fig. $4 C$ ) but did not differ from the distribution of scores in Females $(p>0.50)$.

\section{Total area covered by label}

This measure ignores variations in density of label and simply counts the number of pixels above a minimum background level in each motor nucleus. There was no overall difference among the four experimental groups in the amount of label in the RDLN or DLN (Table 1). Total area covered by label in the SNB did differ by group $(F=10.03 ; p=0.001)$ and was significantly lower in females than in all male groups $(p<0.015$ in each case). This difference may simply reflect the much smaller number of SNB motoneurons in females than in males. To test this assumption, we counted the total number of motoneurons visible in the analyzed sections after neutral red counterstaining. In accord with previous reports (Breedlove and Arnold, 1980; Jordan et al., 1982), we saw no sex difference in motoneuron number in the RDLN (39.7 \pm 2.2 vs $43.6 \pm 4.0$ for males and females, respectively), an approximately twofold sex difference in the DLN $(37.2 \pm 2.2$ vs $18.7 \pm 4.5)$, and a threefold sex difference in the SNB $(30.5 \pm 2.1$ vs $10.4 \pm 2.6)$.

\section{Experiment 2: seven weeks castration and long-term TP replacement}

Two days of TP replacement initiated 4 weeks after castration did not reverse all effects of castration in experiment 1 . We next examined the effect of long-term testosterone replacement in castrates, starting at the time of surgery. Seminal vesicle weights at time of killing indicate that our testosterone capsules provided androgen levels to $\mathrm{Gdx}$ animals that were at least as high as those in sham-Gdx males (Sham, $2173 \pm 327 \mathrm{mg}$; Gdx + Blank, $103 \pm$ $17 \mathrm{mg}$; Gdx + T, $2557 \pm 48 \mathrm{mg})$.

\section{Summary of results}

CNTFR $\alpha$-IR was more intense in motoneuron somata of Sham and Gdx + T males than in Gdx + Blank males for all three cell groups (Fig. 5). Neuropil label was also more intense in Sham than in Gdx + Blank males in all motor pools, and neuropil label in Gdx $+\mathrm{T}$ animals was intermediate. These findings are detailed below.

\section{CNTFR $\alpha$-IR of motoneuron somata and neuropil}

The pattern of results for motoneuron soma densities was identical in the SNB, DLN, and RDLN (Figs. 5, 6). In all cases there was an overall effect of treatment on the relative frequency distributions of cell density measures (SNB: $\chi^{2}=29.5, p<$ 0.0005; DLN: $\chi^{2}=42.1, p<0.0005$; RDLN: $\chi^{2}=19.2, p<$
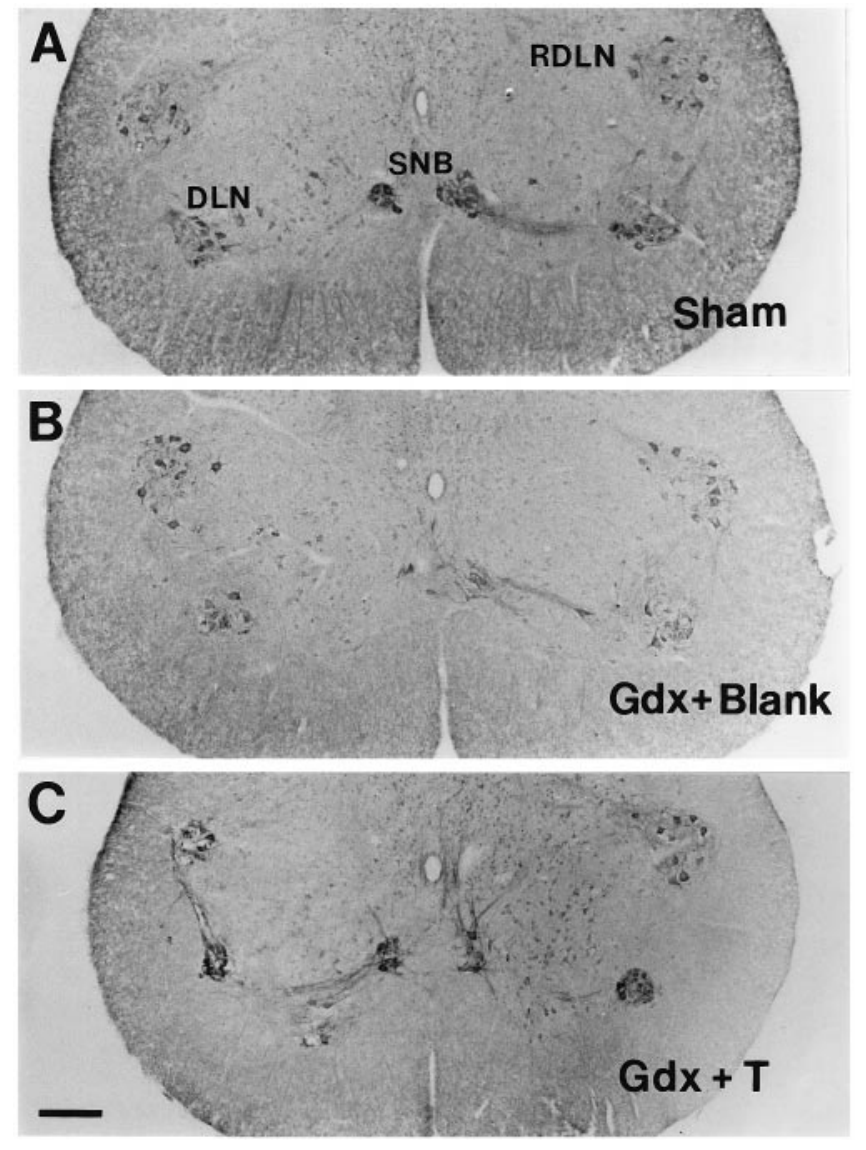

Figure 5. Photomicrographs depicting CNTFR $\alpha$-IR in the lower lumbar spinal cord of Sham $(A), G d x+\operatorname{Blank}(B)$, and $G d x+T(C)$ males. Seven weeks of gonadectomy reduced the intensity of CNTFR $\alpha$-IR in all motor pools, and this decrease was prevented in males receiving testosterone capsules at the time of gonadectomy. Scale bar in $C, 200 \mu \mathrm{m}$ (applies to $A-C$ ).

0.005). Motoneuron soma labeling was shifted to lower values in Gdx + Blank males than in Sham males in each motor pool (SNB, $p<0.002$; DLN, $p<0.001$; RDLN, $p<0.002$ ). Testosterone capsules fully prevented this decrease in castrated males; $\mathrm{Gdx}+\mathrm{T}$ males were not significantly different from the Sham group for any motor pool, and soma densities were shifted to significantly higher values in $\mathrm{Gdx}+\mathrm{T}$ males than in $\mathrm{Gdx}+$ Blank males in each motor pool ( $p<0.002$ in each case).

CNTFR $\alpha$-IR in neuropil also differed by treatment group (Fig. 7; SNB: $\chi^{2}=22.9, p<0.001$; DLN: $\chi^{2}=38.7, p<0.0005$; RDLN: $\left.\chi^{2}=31.3, p<0.0005\right)$. Compared to values in intact males, neuropil densities were shifted to lower scores in gonadectomized males not given hormone replacement $(p<0.001$ for each of the three motor pools). Testosterone capsules only partially prevented the decrease in neuropil labeling, however. Neuropil densities were marginally higher in $\mathrm{Gdx}+\mathrm{T}$ males than in $\mathrm{Gdx}+$ Blank males in the SNB and $\operatorname{RDLN}(p=0.051$ and $p=$ 0.049 , respectively) but not in the DLN $(p=0.10)$. CNTFR $\alpha$-IR in the neuropil of $\mathrm{Gdx}+\mathrm{T}$ and Sham males was equivalent in the SNB $(p>0.15)$ but was lower in Gdx + T males in the DLN and $\operatorname{RDLN}(p<0.001$ in both cases).

Total area covered by label

There was an effect of treatment on the total area covered by label in the SNB and DLN $(F=4.9, p<0.05 ; F=4.4, p<0.05$, 

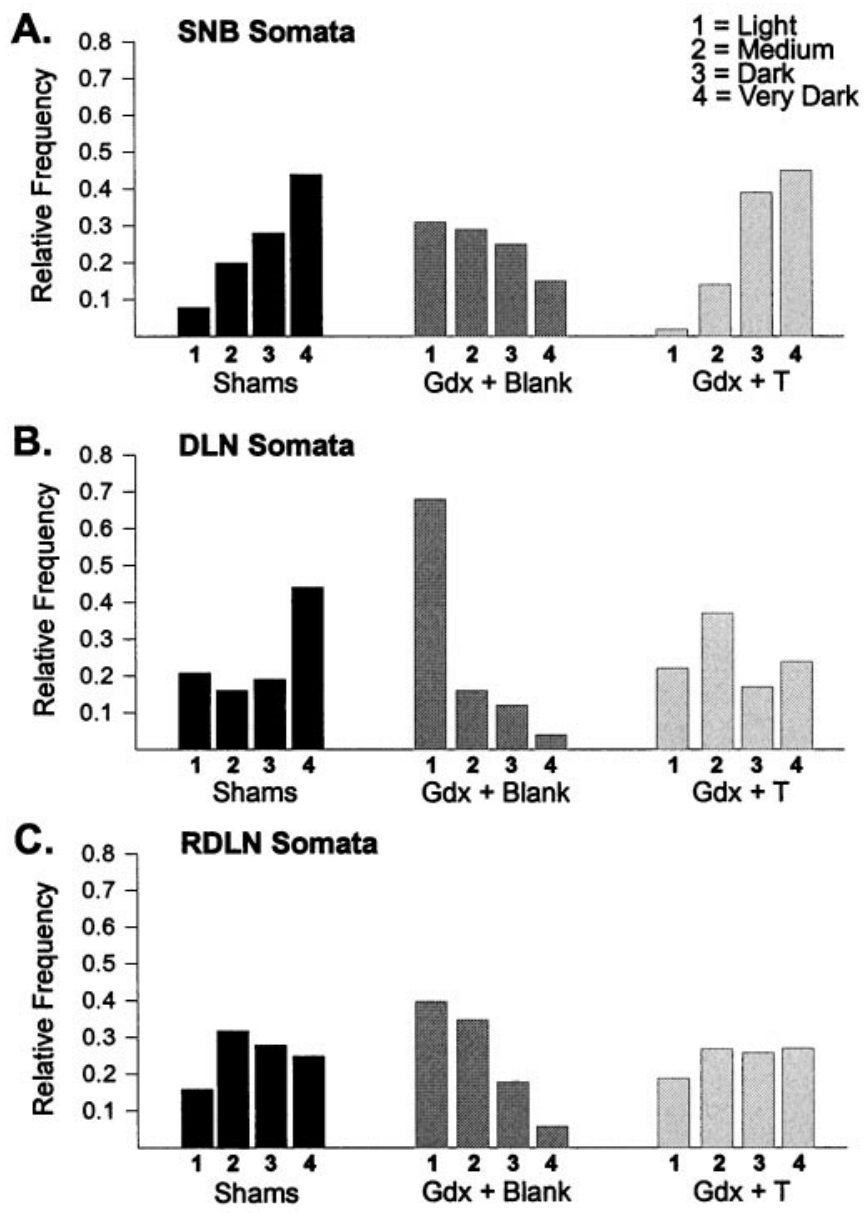

Figure 6. Relative frequency distributions of the percent of motoneuron somata with light, medium, dark, or very dark CNTFR $\alpha$-IR in the SNB $(A)$, DLN $(B)$, and RDLN (C) in experiment 2. CNTFR $\alpha$-IR was shifted to lower scores in motoneurons of $G d x+$ Blank males than in Sham males for each motor pool. Long-term treatment of castrates with testosterone $(G d x+T)$ prevented the decline in label in each case.

respectively) but not in the $\operatorname{RDLN}(F=1.24, p>0.30)$. A greater number of pixels were above threshold in the SNB and DLN of Sham than of Gdx + Blank males ( $p<0.05$ in both cases). Sham and $\mathrm{Gdx}+\mathrm{T}$ males did not differ on this measure in any cell group (Table 2).

\section{DISCUSSION}

We find that spinal motoneurons express CNTFR $\alpha$ in their somata, dendrites, and axons, in confirmation of a previous report (MacLennan et al., 1996). Thus, motoneurons may receive trophic support from CNTF or from other CNTF-like molecules produced by multiple sources, including neural afferents, target muscles, or the peripheral nerve. CNTF itself is expressed at highest levels in Schwann cells of peripheral nerve and does not appear to be made by muscles (Stöckli et al., 1989). However, an additional ligand or ligands for the CNTF receptor likely exist and regulate motoneuron number in development (DeChiara et al., 1995; Shelton, 1996; Forger et al., 1997).

The pattern of CNTFR $\alpha$-IR in the DLN was striking, especially with respect to the very dense, often punctate neuropil staining. Previous ultrastructural studies have reported an extensive bundle of tightly packed dendrites running rostrocaudally through the DLN (Kerns and Peters, 1974; Anderson et al., 1976).
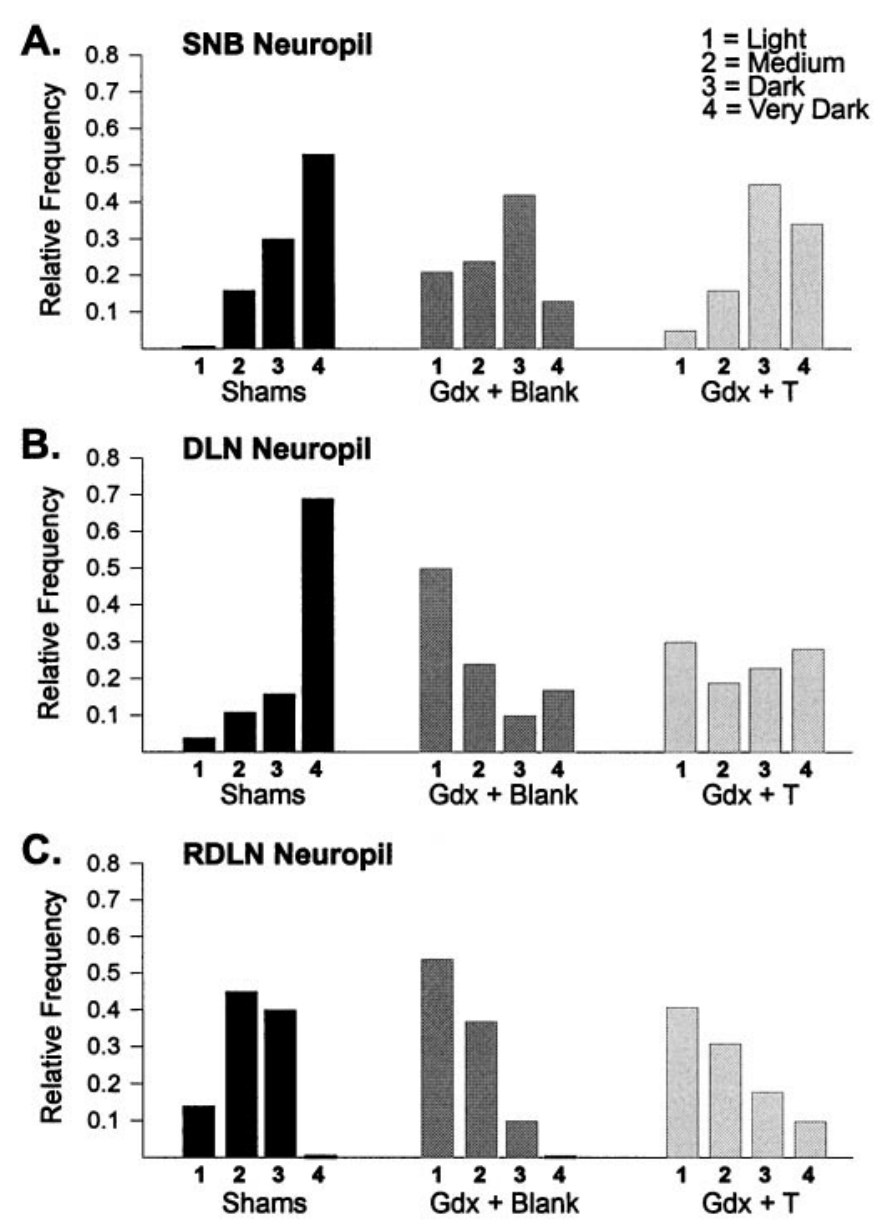

Figure 7. Relative frequency distributions of intensity of CNTFR $\alpha$-IR in the neuropil of animals in experiment 2. Neuropil label was shifted to lower scores in the $G d x+$ Blank group than in the Sham group in each motor pool. CNTFR $\alpha$-IR in the neuropil of $G d x+T$ males was intermediate.

Table 2. Total area covered by label in the RDLN, DLN, and SNB of animals in Experiment 2 (mean \pm SEM) ${ }^{a}$

\begin{tabular}{llll} 
& $\begin{array}{l}\mathrm{RDLN}^{b} \\
\left(\times 10^{3} \text { pixels }\right)\end{array}$ & $\begin{array}{l}\text { DLN } \\
\left(\times 10^{3} \text { pixels }\right)\end{array}$ & $\begin{array}{l}\text { SNB } \\
\left(\times 10^{3} \text { pixels }\right)\end{array}$ \\
\hline Shams & $73.3 \pm 4.5$ & $59.1 \pm 7.9$ & $76.1 \pm 11.0$ \\
Gdx + Blank & $63.4 \pm 3.4$ & $34.4 \pm 3.5^{*}$ & $46.1 \pm 0.5^{*}$ \\
Gdx $+\mathrm{T}$ & $68.9 \pm 5.3$ & $52.7 \pm 7.8$ & $72.5 \pm 15.6$
\end{tabular}

$\overline{{ }^{a} \text { For each animal the number of pixels covered by label was summed across five }}$ sections, $n=4$ animals per group.

${ }^{b}$ The RDLN and DLN were measured unilaterally; the SNB was measured bilaterally.

*Significantly different from Shams and Gdx + Blank, $p<0.05$.

These dendrites are interspersed among the motoneuronal somata and originate from the DLN motoneurons themselves. It seems likely, therefore, that CNTFR $\alpha$-IR in the DLN neuropil is caused primarily by CNTFR $\alpha$ protein present on DLN dendrites, which would have been cut in cross section in our coronal sections. The labeling we observed in the SNB also matches previous descriptions of the dendritic projections of SNB motoneurons (Kurz et al., 1986; Rand and Breedlove, 1995), and horizontal sections did not reveal any major input of CNTFR $\alpha$ immunoreactive fibers to the SNB/DLN/RDLN area from 
higher or lower in the neuraxis (Fig. $2 A$ ). Taken together, we conclude that most of the CNTFR $\alpha$-IR in the neuropil came from the dendrites of motoneurons within each motor pool.

Castration of adult male rats caused a decrease in CNTFR $\alpha$-IR in the somata of motoneurons of the SNB, DLN, and RDLN. Short-term ( $2 \mathrm{~d}$ ) testosterone treatment reversed the decline in soma labeling in the SNB only, and long-term (7 weeks) testosterone replacement prevented the decline in all three cell groups. Adult castration also results in a reduction in motoneuron soma size in the SNB and, to a lesser extent, the DLN (Breedlove and Arnold, 1981; Kurz et al., 1991). An effect on soma size is not likely to have contributed to the changes we observed in soma labeling, however. If the same number of CNTFR $\alpha$ molecules were distributed over smaller somata, one would expect the intensity of label on somata to be increased in castrated males. Instead, the opposite pattern was found, indicating a downregulation of CNTFR $\alpha$ protein after castration. Motoneuron soma labeling was also more intense in intact males than in females in all three motor pools. The lower circulating androgen levels in females than in males may result in reduced expression of CNTFR $\alpha$ in motoneurons of females.

Seven weeks of castration reduced the intensity of CNTFR $\alpha$-IR in the neuropil of each motor pool. Within the RDLN, the reduction in neuropil labeling occurred in the absence of any effect of castration on the total area covered by label. That is, the total number of pixels above background in the RDLN was equivalent in intact and gonadectomized males, but the average intensity of label in the neuropil was reduced by gonadectomy. We interpret this finding as a reduction in CNTFR $\alpha$-IR per unit length of dendrite in the RDLN of castrated males. The interpretation of effects of castration on neuropil labeling in the SNB and DLN is less straightforward, however. We reason that the intensity of label in neuropil will be influenced by both the amount of label per unit area of dendrite as well as the number of dendrites ramifying in a given area. The dendritic arbors of SNB and DLN motoneurons are reported to retract after castration, although there is some debate as to whether the effect is large (Kurz et al., 1986, 1991) or rather subtle (Sasaki and Arnold, 1991). We observed a significant reduction in total area covered by label in the SNB and DLN of Gdx + Blank males (Table 2), which may reflect an attenuation of dendritic trees after castration. Thus, the decrease in intensity of label in the neuropil of the SNB and DLN of Gdx + Blank males may be caused in part by a reduction in the number of dendritic branches per unit area of neuropil. It is worth noting, however, that even if all effects of gonadectomy on intensity of label in neuropil and total area covered by label are accounted for by a reduction in motoneuron size, the end result would nevertheless be fewer CNTF receptors per motoneuron and, presumably, reduced sensitivity to trophic factor support in gonadectomized males.

Because testosterone itself is an androgen, the present results demonstrate androgenic control of CNTFR $\alpha$-IR in spinal motoneurons. However, testosterone can be aromatized to estradiol, and at present we cannot rule out the possibility that the observed effects of castration and testosterone replacement were actually mediated by estrogenic hormone metabolites. Resolving this issue would be of interest because the three motor pools examined in this study all express androgen receptors but do not exhibit estrogen-binding activity (Breedlove and Arnold, 1980, 1983; Freeman et al., 1995; Jordan et al., 1997). Identifying the active hormone metabolite or metabolites would, therefore, help to resolve the question of whether effects of testosterone on
CNTFR $\alpha$-IR in spinal motoneurons is likely to be mediated directly at the motoneurons themselves or indirectly via hormone action on target muscles, afferents, or other intermediaries.

Several previous studies have demonstrated that CNTFR $\alpha$ mRNA levels in the brain and spinal cord are altered after nervous system injury (Mata et al., 1993; Rudge et al., 1994; Lee et al., 1997a,c; Oyesiku et al., 1997). However, very little has been reported regarding factors that regulate the expression of CNTFR $\alpha$ under physiological, noninjury conditions. By Northern blotting we recently found that adult castration alters the level of CNTFR $\alpha$ mRNA in the target muscles of SNB motoneurons but has no effect on the abundance of CNTFR $\alpha$ message in homogenates of the whole lumbosacral spinal cord ( $\mathrm{Xu}$ and Forger, 1998). Because many cell types are present in the cord, we could not discern by Northern blotting whether CNTFR $\alpha$ expression might be androgen-regulated in specific subsets of cells. The present analysis indicates that at least at the protein level, circulating androgen levels do alter $\mathrm{CNTFR} \alpha$ expression in spinal motoneurons. This is true not only for sexually dimorphic penile motoneurons (SNB, DLN), but also for motoneurons innervating foot muscles (RDLN).

Previously, androgens have been shown to regulate the expression of calcitonin gene-related peptide, cholecystokinin, $\beta$-tubulin, $\beta$-actin, and connexin mRNAs in SNB motoneurons (Popper et al., 1992; Matsumoto et al., 1994, 1995). In addition, vasopressin-binding sites on SNB motoneurons are downregulated by castration (Tribollet et al., 1997). In each case, however, androgen manipulations had no effect on gene expression in the RDLN, or in other motoneurons innervating muscles that are not sexually dimorphic. Although most brainstem and spinal motoneurons express androgen receptors (Sar and Stumpf, 1977; Yu and McGinnis, 1986), as far as we are aware only choline acetyltransferase mRNA has previously been shown to be regulated by androgens in all motor pools examined (Blanco et al., 1997). We did not quantify CNTFR $\alpha$ expression in the few cervical and thoracic cords examined in the present study. Nonetheless, our observation that testosterone regulates $\mathrm{CNTFR} \alpha$ protein in the RDLN suggests that androgen regulation of $\mathrm{CNTFR} \alpha$ protein may be a general property of spinal motoneurons.

The present results are particularly interesting in light of the fact that androgens have trophic effects on spinal and brainstem motoneurons. In addition to the actions of androgens on SNB and DLN cell size discussed above, the rate of motor nerve regeneration is enhanced by testosterone in adult rodents ( Yu, 1982; Kujawa et al., 1993, 1995). Testosterone also rescues SNB and DLN motoneurons from developmental cell death in perinatal rats (Nordeen et al., 1985; Sengelaub and Arnold, 1989) and attenuates motoneuron death after axotomy of the laryngeal nerve in adult frogs (Pérez and Kelley, 1996). Finally, message for choline acetyltransferase (ChAT) is reduced in spinal motoneurons of male rats by castration and is increased by testosterone treatment (Blanco et al., 1997). These hormone effects are remarkably similar to the actions of CNTF on peripheral nerve regeneration, motoneuron survival, and motoneuron ChAT activity (Wong et al., 1993; Forger et al., 1993; Kato and Lindsay, 1994; Sahenk et al., 1994; Ulenkate et al., 1994). By upregulating CNTFR $\alpha$ protein expression in spinal motoneurons, testosterone presumably increases motoneuron responsiveness to $\mathrm{CNTFR} \alpha$ ligands. This increased responsivity to trophic support could underlie androgenic effects on motoneuron survival, cell size, or axon regeneration. 


\section{REFERENCES}

Anderson WJ, Stromberg MW, Hinsman EJ (1976) Morphological characteristics of dendritic bundles in the lumbar spinal cord of the rat. Brain Res 110:215-227.

Arakawa Y, Sendtner M, Thoenen H (1990) Survival effect of ciliary neurotrophic factor (CNTF) on chick embryonic motoneurons in culture: comparison with other neurotrophic factors and cytokines. J Neurosci 10:3507-3515.

Barbin G, Manthorpe M, Varon SJ (1984) Purification of the chick eye ciliary neuronotrophic factor. J Neurochem 43:1468-1478.

Blanco CE, Popper P, Micevych P (1997) Anabolic-androgenic steroid induced alterations in choline acetyltransferase messenger RNA levels of spinal cord motoneurons in the male rat. Neuroscience 78:873-882.

Breedlove SM, Arnold AP (1980) Hormone accumulation in a sexually dimorphic motor nucleus in the rat spinal cord. Science 210:564-566.

Breedlove SM, Arnold AP (1981) Sexually dimorphic motor nucleus in the rat lumbar spinal cord: response to adult hormone manipulation, absence in androgen-insensitive rats. Brain Res 225:297-307.

Breedlove SM, Arnold AP (1983) Sex differences in the pattern of steroid accumulation by motoneurons of the rat lumbar spinal cord. J Comp Neurol 215:211-216.

Clarke PGH, Oppenheim RW (1995) Neuron death in vertebrate development: in vivo methods. Methods Cell Biol 46:277-321.

Davis S, Aldrich TH, Valenzuela DM, Wong V, Furth ME, Squinto SP, Yancopoulos GD (1991) The receptor for ciliary neurotrophic factor. Science 253:59-63.

Davis S, Aldrich TH, Stahl N, Pan L, Taga T, Kishimoto T, Ip NY, Yancopoulos GD (1993) LIFR $\beta$ and gp130 as heterodimerizing signal transducers of the tripartite CNTF receptor. Science 260:1805-1808.

DeChiara TM, Vejsada R, Poueymirou WT, Acheson A, Suri C, Conover JC, Friedman B, McClain J, Pan L, Stahl N, Ip NY, Kato A, Yancopoulos GD (1995) Mice lacking the CNTF receptor, unlike mice lacking CNTF, exhibit profound motor neuron deficits at birth. Cell 83:313-322.

Forger NG, Roberts SL, Wong V, Breedlove SM (1993) Ciliary neurotrophic factor maintains motoneurons and their target muscles in developing rats. J Neurosci 13:4720-4726.

Forger NG, Howell ML, Bengston L, MacKenzie L, DeChiara TM, Yancopoulos GD (1997) Sexual dimorphism in the spinal cord is absent in mice lacking the ciliary neurotrophic factor receptor. J Neurosci 17:9605-9612.

Freeman LM, Padgett BA, Prins GS, Breedlove SM (1995) Distribution of androgen receptor immunoreactivity in the spinal cord of wild-type, androgen-insensitive, and gonadectomized male rats. J Neurobiol 27:51-59.

Gurney ME, Yamamoto H, Kwon Y (1992) Induction of motor neuron sprouting in vivo by ciliary neurotrophic factor and basic fibroblast growth factor. J Neurosci 12:3241-3247.

Ikeda K, Wong V, Holmlund TH, Greene T, Cedarbaum JM, Lindsay RM, Mitsumoto H (1995) Histomeric effects of ciliary neurotrophic factor in wobbler mouse motor neuron disease. Ann Neurol 37:47-54.

Ip NY, McClain J, Barrezueta NX, Aldrich, TH, Pan L, Li Y, Wiegand SJ, Friedman B, Davis S, Yancopoulos GD (1993) The $\alpha$ component of the CNTF receptor is required for signaling and defines potential CNTF targets in the adult and during development. Cell 10:89-102.

Jordan CL (1996) Morphological effects of ciliary neurotrophic factor treatment during neuromuscular synapse elimination. J Neurobiol $31: 29-40$.

Jordan CL, Breedlove SM, Arnold AP (1982) Sexual dimorphism and the influence of neonatal androgen in the dorsolateral motor nucleus of the rat lumbar spinal cord. Brain Res 249:309-314.

Jordan CL, Padgett B, Hershey J, Prins G, Arnold AP (1997) Ontogeny of androgen receptor immunoreactivity in lumbar motoneurons and in the sexually dimorphic levator ani muscle of male rats. J Comp Neurol 379:88-98.

Kato AC, Lindsay RM (1994) Overlapping and additive effects of neurotrophins and CNTF on cultured human spinal cord neurons. Exp Neurol 130:196-201.

Kerns JM, Peters A (1974) Ultrastructure of a large ventro-lateral dendritic bundle in the rat ventral horn. J Neurocytol 3:533-555.

Konigsmark BW (1970) Methods for the counting of neurons. In: Contemporary research methods in neuroanatomy (Nauta WJH, Ebbesson SOE, eds), pp 315-340. New York: Springer.

Kujawa KA, Jones KJ (1990) Testosterone-induced acceleration of re- covery from facial paralysis in male hamsters: temporal requirements of hormone exposure. Physiol Behav 48:765-768.

Kujawa KA, Jacob JM, Jones KJ (1993) Testosterone regulation of the regenerative properties of injured rat sciatic motor neurons. J Neurosci Res 35:268-273.

Kujawa KA, Tanzer L, Jones KJ (1995) Inhibition of the accelerative effects of testosterone on HFMN regeneration by the antiandrogen flutamide. Exp Neurol 133:138-143.

Kurz EM, Sengelaub DR, Arnold AP (1986) Androgens regulate the dendritic length of mammalian motoneurons in adulthood. Science 232:395-398.

Kurz EM, Brewer RG, Sengelaub DR (1991) Hormonally mediated plasticity of motoneuron morphology in the adult rat spinal cord: a cholera toxin-HRP study. J Neurobiol 22:976-988.

Lee M-Y, Deller T, Kirsch M, Frotscher M, Hofmann H-D (1997a) Differential regulation of ciliary neuronotrophic factor (CNTF) and CNTF receptor $\alpha$ expression in astrocytes and neurons of the fascia dentata after entorhinal cortex lesion. J Neurosci 17:1137-1146.

Lee M-Y, Hofmann H-D, Kirsch M (1997b) Expression of ciliary neurotrophic factor receptor- $\alpha$ messenger RNA in neonatal and adult rat brain: an in situ hybridization study. Neuroscience 77:233-246.

Lee M-Y, Naumann T, Kirsch M, Frotscher M, Hofmann H-D (1997c) Transient up-regulation of ciliary neurotrophic factor receptor- $a$ mRNA in axotomized rat septal neurons. Eur J Neurosci 9:622-626.

MacLennan AJ, Gaskin AA, Lado DC (1994) CNTF receptor $\alpha$ mRNA expression in rodent cell lines and developing rat. Mol Brain Res 25:251-256.

MacLennan AJ, Vinson EN, Marks L, McLaurin DL, Pfeifer M, Lee N (1996) Immunohistochemical localization of ciliary neurotrophic factor receptor $\alpha$ expression in the rat nervous system. J Neurosci 16:621-630.

Masu Y, Wolf, E, Holtman B, Sendtner M, Brem G, Thoenen H (1993) Disruption of the CNTF gene results in motor neuron degeneration. Nature 365:27-32.

Mata M, Jin C-F, Rink DJ (1993) Axotomy increases CNTF receptor mRNA in rat spinal cord. Brain Res 610:162-165.

Matsumoto A, Arai Y, Urano A, Hyodo S (1994) Androgen regulates gene expression of cytoskeletal proteins in adult rat motoneurons. Horm Behav 28:357-366.

Matsumoto A, Arai Y, Urano A, Hyodo S (1995) Molecular basis of neuronal plasticity to gonadal steroids. Funct Neurol 10:59-76.

Mitsumoto H, Ikeda K, Klinkosz B, Cedarbaum JM, Wong V, Lindsay RM (1994) Arrest of motor neuron disease in wobbler mice cotreated with CNTF and BDNF. Science 265:1107-1110.

Nicolopoulos-Stournaras S, Iles JF (1983) Motor neuron columns in the lumbar spinal cord of the rat. J Comp Neurol 217:75-85.

Nordeen EJ, Nordeen KW, Sengelaub DR, Arnold AP (1985) Androgens prevent normally occurring cell death in a sexually dimorphic spinal nucleus. Science 229:671-673.

Oppenheim R, Prevette D, Qin-Wei Y, Collins F, MacDonald J (1991) Control of embryonic motoneuron survival in vivo by ciliary neurotrophic factor. Science 251:1616-1618.

Oyesiku NM, Wilcox JN, Wigston DJ (1997) Changes in expression of ciliary neurotrophic factor (CNTF) and the CNTF-receptor $\alpha$ after spinal cord injury. J Neurobiol 32:251-261.

Pérez J, Kelley DB (1996) Trophic effects of androgen: receptor expression and the survival of laryngeal motor neurons after axotomy. J Neurosci 16:6625-6633.

Popper P, Abelson L, Micevych PE (1992) Differential regulation of $\alpha$-calcitonin gene-related peptide and preprocholecystokinin messenger RNA expression in $\alpha$ motoneurons: effects of testosterone and inactivity induced factors. Neuroscience 51:87-96.

Rand MN, Breedlove SM (1995) Androgen alters the dendritic arbors of SNB motoneurons by acting upon their target muscles. J Neurosci 15:4408-4416.

Rudge JS, Li Y, Rasnikowski EM, Mattson K, Pan L, Yancopoulos GS, Wiegand SJ, Lindsay RM, Ip NY (1994) Neurotrophic factor receptors and their signal transduction capabilities in rat astrocytes. Eur J Neurosci 6:693-705.

Sagot Y, Tan SA, Baetge E, Schmalbruch H, Kato AC, Aebischer P (1995) Polymer encapsulated cell lines genetically engineered to release ciliary neurotrophic factor can slow down progressive motor neuronopathy in the mouse. Eur J Neurosci 7:1313-1322.

Sahenk Z, Seharaseyon J, Mendell JR (1994) CNTF potentiates peripheral nerve regeneration. Brain Res 655:246-250. 
Sar M, Stumpf WE (1977) Androgen concentration in motor neurons of cranial nerves and spinal cord. Science 197:77-79.

Sasaki M, Arnold AP (1991) Androgenic regulation of dendritic trees of motoneurons in the spinal nucleus of the bulbocavernosus: reconstruction after intracellular iontophoresis of horseradish peroxidase. J Comp Neurol 308:11-27.

Schroder HD (1980) Organization of the motoneurons innervating the pelvic muscles of the male rat. J Comp Neurol 192:567-587.

Sendtner M, Kreutzberg GW, Thoenen H (1990) Ciliary neurotrophic factor prevents the degeneration of motor axons after axotomy. Nature 345:440-441.

Sendtner M, Schmalbruch H, Stöckli KA, Carroll P, Kreutzberg GW, Thoenen H (1992) Ciliary neurotrophic factor prevents degeneration of motor neurons in mouse mutant progressive motor neuronopathy. Nature 358:502-504.

Sengelaub DR, Arnold AP (1989) Hormonal control of neuron number in sexually dimorphic spinal nuclei of the rat: I. Testosterone-regulated death in the dorsolateral nucleus. J Comp Neurol 280:622-629.

Shelton DL (1996) Are there more members of the CNTF-GPA family? Perspect Dev Neurobiol 4:101-107.

Smith ER, Damassa DA, Davidson JM (1977) Hormone administration: peripheral and intracranial implants. In: Methods in psychobiology, Vol 3, (Meyers RD, ed), pp 259-279. New York: Academic.
Stöckli KA, Lottspeich F, Sendtner M, Masiakowski P, Carroll P, Götz R, Lindholm D, Thoenen H (1989) Molecular cloning, expression and regional distribution of rat ciliary neurotrophic factor. Nature 342:920-923.

Tribollet E, Barberis C, Arsenijevic Y (1997) Distribution of vasopressin and oxytocin receptors in the rat spinal cord: sex-related differences and effect of castration on pudendal motor nuclei. Neuroscience 78:499-509.

Ulenkate HJLM, Kaal ECA, Gispen W-H, Jennekens FGI (1994) Ciliary neurotrophic factor improves muscle fibre reinnervation after facial nerve crush in young rats. Acta Neuropathol 88:558-564.

Wong V, Arriage R, Ip NY, Lindsay RM (1993) The neurotrophins BDNF, NT-3 and NT 4/5, but not NGF, up-regulate the cholinergic phenotype of developing motor-neurons. Eur J Neurosci 5:466-474.

Xu J, Forger NG (1998) Expression and androgen regulation of the ciliary neurotrophic factor receptor $(\mathrm{CNTFR} \alpha)$ in muscles and spinal cord. J Neurobiol 35:217-225.

Yu W-HA (1982) Effect of testosterone on the regeneration of the hypoglossal nerve in rats. Exp Neurol 77:129-141.

$\mathrm{Yu}$ W-HA, McGinnis MY (1986) Androgen receptor levels in cranial nerve nuclei and tongue muscles in rats. J Neurosci 6:1302-1307. 